\title{
UMA HISTÓRIA ORAL EM TRÊS TEMPOS: RELAÇÕES, CONSTRUÇÕES NARRATIVAS, USOS PRÁTICOS DA MEMÓRIA
}

An oral history in three times: relationships, narrative constructions, practical uses of memory

Una historia oral en tres tiempos: relaciones, construcciones narrativas, usos prácticos de la memoria

RICARDO SANTHIAGO ${ }^{\text {* }}$

DAPHNE PATAI ${ }^{\mathrm{II} * *}$

https://doi.org/10.1590/S2178-149420210302

'Universidade Federal de São Paulo - São Paulo (SP), Brasil.

*Doutor em História (ricardo.santhiago@unifesp.br)

(D) https://orcid.org/0000-0001-5318-5801

"University of Massachusetts (UMass) - Amherst (MA), Estados Unidos.

**Doutora em Literatura Brasileira (daphne.patai@spanport.umass.edu)

(D) https://orcid.org/0000-0001-5192-1879

Artigo recebido em 01 de maio de 2021 e aprovado para publicação em 09 de julho de 2021. 


\title{
RESUMo
}

Este artigo resulta de um projeto que coletou entrevistas de história oral, nos anos 2010, com mulheres que já haviam se narrado três décadas antes, em outro contexto de pesquisa. Os depoimentos de uma das narradoras do projeto, Marialice, gravados em 1981, 1983 e 2015, são discutidos aqui à luz de quatro eixos. 0 primeiro deles, metodológico, problematiza as relações intersubjetivas estabelecidas em uma pesquisa projetada no tempo e em diálogo com o desenvolvimento da literatura de história oral entre os anos 1980 e 2010. Os demais, interpretativos, avaliam a construção sintagmática da narrativa de Marialice; os padrões narrativos mobilizados por ela em sua construção de si; e, finalmente, os usos práticos de sua própria história pessoal.

PALAVRAS-CHAVE: História Oral; Pesquisa Narrativa; Relação; Pesquisa Participativa.

\begin{abstract}
This article is the result of a project that collected oral history interviews, in the 2010s, with women who had already narrated their stories three decades before, in a different research context. The testimonies of one of the narrators, Marialice, recorded in 1981, 1983 and 2015, are discussed here, in four steps. First, using a methodological approach, we discuss the intersubjective relations established in research projected over time and in dialogue with the development of oral history scholarship between the 1980s and the 2010s. Then, in an interpretive approach, we evaluate the syntagmatic construction of Marialice's narrative; the narrative patterns she mobilizes; and, finally, the practical uses to which she puts her own personal history.
\end{abstract}

KEYWORDS: Oral History; Narrative Research; Relationships; Participatory Research.

\section{RESUMEN}

Este artículo es el resultado de un proyecto que recogió entrevistas de historia oral, en los años 2010, con mujeres que ya se habían narrado a sí mismas tres décadas antes, en otro contexto de investigación. Se discuten aquí los testimonios de una de las narradoras del proyecto, Marialice, registrados en 1981, 1983 y 2015, a la luz de cuatro ejes. El primero, metodológico, cuestiona las relaciones intersubjetivas que se establecen en una investigación proyectada en el tempo y en diálogo con el desarrollo de la literatura de historia oral entre los años 1980 y 2010. Los otros, interpretativos, valoran la construcción sintagmática de la narrativa de Marialice; los patrones narrativos movilizados por ella en su construcción de sí misma; y, finalmente, los usos prácticos de su propia historia personal.

PALABRAS CLAVE: Historia Oral; Investigación Narrativa; Relación; Investigación Participativa. 


\section{HISTÓRIA ORAL: LUGAR DE MÚLTIPLAS RELAÇÕES}

$\mathrm{E}$

ste texto, a exemplo de qualquer outro que tenha a história oral como seu esteio, é fruto de relações entre indivíduos diferentes, reunidos artificial, provisória e circunstancialmente em função de uma situação de pesquisa. É fruto, igualmente, de relações entre espaços, temporalidades e repertórios culturais distintos, triangulados a partir do entendimento de que a história oral é mais do que uma técnica específica de pesquisa narrativa: é também a ignição para trocas de experiências com ressonâncias pessoais e intelectuais profundas. Remetido a um dossiê que busca refletir sobre os ajustamentos da história oral aos desafios de seu tempo, este texto tem um trajeto que também reflete algumas das transformações pelas quais 0 método e seus praticantes passaram no arco dos últimos 40 anos. Foi em 1981, afinal, que uma das autoras deste artigo, Daphne Patai — estudando literatura e cultura brasileira e, àquela altura, comprometida com o feminismo — visitou o Brasil para uma aventura pessoal e intelectual diferentes das anteriores, munida desta vez de um presente inesperado recebido de seu marido, o historiador Gerald Strauss: um gravador cassete Panasonic.

Nessa viagem que durou algumas semanas, e em uma segunda visita feita em 1983, gravou 60 longas entrevistas com mulheres brasileiras nas cidades do Rio de Janeiro, Recife e João Pessoa. Como muitos pesquisadores que depois se engajaram em debates metodológicos, teóricos, éticos e políticos sobre história oral, introduziu-se a ela a partir da prática. Além de não ser um termo largamente popular, a história oral era também uma área com acúmulo limitado; suas convicções procedimentais eram desafiadas com frequência no interior de um circuito intelectual no qual dados estatísticos, pesquisas quantitativas e documentos escritos prevaleciam.

Com reduzida literatura ao seu alcance, esta autora ingressou - como muitos de seus contemporâneos, cabe repetir - em um terreno de pesquisa ainda por ser explorado. Depois das gravações com essas mulheres, vieram as transcrições das falas, as conferências de fidelidade, os experimentos de edições, as difíceis traduções (não apenas linguísticas, mas transculturais), os enquadramentos manifestos em textos de apresentação das narradoras, orientados à produção daquilo que viria a ser o livro Brazilian women speak: contemporary life stories, publicado em 1988. Foi à medida que trabalhou nessa obra que Daphne se aproximou mais enfaticamente da literatura, ainda não facilmente acessível, de história oral.

0 que se buscou produzir naquele momento foi um livro voltado não ao público brasileiro, nem aos interessados na metodologia da história oral, mas sim endereçado às mulheres norte-americanas, que poderiam entrar em contato com experiências até então desconhecidas. Aliás, era esse o espírito que conduzia a aproximação entre história oral e o feminismo, naquela época: a documentação de vidas ignoradas por meio de um recurso de trabalho que 
não era apenas sobre as mulheres, mas por e para as mulheres, como se analisou em uma revisão crítica, muito tempo depois (Patai, 2008).

0 outro autor deste artigo, Ricardo Santhiago, acrescentaria que Brazilian women speak compartilha com a história pública a mesma inspiração dirigida ao fortalecimento da dimensão participativa na construção de saberes sobre o passado e à potencialização da comunicação pública. Ricardo conheceu Brazilian women speak muitos anos depois de sua publicação, em 2005 ou 2006. Naquela ocasião, preparava seu projeto de mestrado — também dedicado a escutar mulheres brasileiras - e tomou o livro de Daphne como um modelo para seus procedimentos e sua composição. Ao contrário da autora, porém, Ricardo possuía ao seu alcance um vasto instrumental metodológico, conceitual e teórico, acumulado pela área de história oral, no exterior e no Brasil (onde ela se consolidou a partir dos anos 1990). Pôde mobilizar e combinar abordagens sobre a história oral - valendo-se do legado de quem, como Daphne, aprendeu ao longo da própria prática.

Daphne e Ricardo, mais tarde, iniciaram uma correspondência e uma relação de trabaIho que veio a acender uma centelha e oportunizar a possibilidade desafiadora de revisitação de Brazilian women speak por meio de novos encontros com as mulheres originalmente ouvidas por Daphne em 1981 e 1983. Entre 2014 e 2017, um material rico foi coligido por Ricardo nas cidades de Rio de Janeiro, Aracaju, Recife e João Pessoa: testemunhos de quase duas dezenas das 60 mulheres entrevistadas, número substancial tendo em vista os muitos efeitos do tempo — incluindo mudanças, doenças e mortes que impossibilitaram a localização de todas as antigas narradoras — sobre uma pesquisa que não se pretendeu longitudinal'.

A preservação dos materiais de pesquisa originais, por Daphne, permitiu ainda reouvir e digitalizar as entrevistas gravadas em fita cassete; acessar os formulários com dados das entrevistadas e as primeiras versões das transcrições, várias delas com apontamentos manuscritos; rever as notas de campo, feitas no calor da hora; ler a correspondência com a editora que trouxe o livro à luz, com comentários que reorientaram sua composição; e consultar as cartas trocadas entre Daphne e algumas de suas entrevistadas nos anos que se seguiram. A nova pesquisa, ainda, gerou uma correspondência entre Daphne e Ricardo, separados por mais de 8 mil quilômetros de distância: uma espécie de caderno de campo a quatro mãos, viabilizado pela instantaneidade do correio eletrônico. 0 volume do material tem exigido uma elaboração lenta e cuidadosa de resultados - e a experimentação de formatos em artigos como este? ${ }^{2}$.

Além das narrativas de vida colhidas em três tempos e das histórias de seus processos de elaboração e documentação, a multiplicidade de abordagens possíveis representa um outro desafio. Assim como são muitas as maneiras de olhar para o desenvolvimento da história oral, como área, ao longo do tempo, também são numerosos os caminhos interpretativos para 
as histórias elicitadas e verbalizadas em tempos, espaços, e para interlocutores diferentes. Neste artigo, discutimos uma dessas histórias à luz de três eixos: um deles mais propriamente metodológico (as relações estabelecidas em uma pesquisa alongada no tempo) e três interpretativos (a construção sintagmática de uma narrativa pessoal; os padrões narrativos mobilizados na construção de si; e os usos práticos das histórias pessoais).

\section{UM PROJETO EM UMA VIDA}

M arialice foi uma das mulheres, com percursos de vida diferentes, que Daphne entrevistou na cidade de João Pessoa. Valendo-se da rede de contatos estabelecida a partir de seu amigo e ex-companheiro Joel — um homem paraibano que conhecera nos anos 1960, nos Estados Unidos, quando ele fazia mestrado na Universidade de Wisconsin - Daphne chegou a integrantes e amigas daquela família e a mulheres que serviam como suas empregadas. À época com 29 anos, Marialice trabalhava como faxineira no escritório do pai de Joel. A primeira entrevista aconteceu no dia 20 de agosto de 1981 na casa da irmã mais velha de Joel. Dois verões americanos depois, em setembro de 1983, Marialice e Daphne reencontraram-se para uma nova sessão.

Ambos os encontros foram relativamente longos, rendendo, cada um, cerca de trinta páginas datilografadas. Nessas entrevistas de história de vida, Marialice narra-se eloquente e generosamente a uma interlocutora desconhecida. Na primeira das entrevistas, fala sobre suas origens familiares, seu casamento, sua mudança do pequeno município de Araruna, no interior da Paraíba, para a capital. 0 episódio curioso de uma falsa gravidez é o que mais salta aos ouvidos. Da mesma forma, embora no segundo encontro — mais extenso e relaxado Marialice tome a palavra para se queixar da inflação e das dificuldades financeiras, são o amor e a devoção por sua mãe que the dão cor e sabor.

Os encontros entre Daphne e Marialice foram mais do que gravações protocolares ou encontros particularmente significativos para uma pesquisa. Criaram uma espécie de vínculo que durou vários anos, alimentado por cartas esparsas, mas periódicas. Daphne não se lembra como a correspondência começou, mas suspeita que tenha sido em resposta à carta de agradecimento que enviou dos Estados Unidos a tantas entrevistadas quanto pôde — nem todas, já que várias não possuíam endereço fixo. Depois disso, Marialice era quem costumava tomar a iniciativa de escrever. Enviou pouco mais de uma dezena de cartas, um par delas em 1983, outras até o fim da década de 1980.

As cartas dão sobrevida à oralidade que fundou a relação: energicamente eloquente, mas praticamente analfabeta, Marialice as ditava para conhecidos, que também liam para ela a via que chegava. Algumas são datilografadas e outras escritas a mão, com caligrafias dife- 
rentes e graus variados de formalidade e domínio da língua. Seria difícil precisar a influência desses escrevedores no conteúdo das cartas, mas em algumas delas é possível perceber que o estilo, o vocabulário e as ideias pertencem também a eles ${ }^{3}$. Em suas cartas, Marialice não apenas dava notícia de si e de sua família, mas também descrevia seu calvário de pobreza e humilhação social — e, ora implícita ora explicitamente, pedia o auxílio de quem tratava como uma amiga próxima.

Tendo entrevistado mais de uma dezena de mulheres realmente pobres, Daphne jamais as remunerou pelas entrevistas - um tópico sensível na literatura da área de história oral. Ela escreveu a respeito em 1987 para o hoje descontinuado International Journal of Oral History, em um artigo que levantava as questões éticas àquela altura incômodas e praticamente rarefeitas nos círculos de discussão da área. Sob o título "Ethical problems in personal narratives, or, who should eat the last piece of cake?" (Patai, 1987), o artigo não pretendia "oferecer soluções" para os dilemas éticos envolvidos na pesquisa com história oral, mas questionava duramente as assimetrias sociais e econômicas implicadas particularmente em uma pesquisa transcultural como aquela ${ }^{4}$. Daphne reconhecia:

Ao longo do trabalho, e de uma forma diferente dos meus contatos anteriores com o Brasil, eu me afligia com a miséria completa de algumas das pessoas que entrevistava, com minhas possibilidades limitadas de oferecer ajuda prática, e até mesmo com os problemas relacionados à oferta dessa ajuda, que sinalizava claramente o paternalismo e a reintrodução de uma hierarquia por vezes ausente na intensa intimidade da situação de entrevista. (Patai, 2010: 68-69).

Finalizadas as entrevistas, no entanto, Daphne ajudou Marialice (bem como outra de suas entrevistadas, Norma) $)^{5}$ financeiramente. Mais de trinta anos depois, seria difícil lembrar como esse auxílio se iniciou e porquê, mas as cartas o esclarecem. Nelas, a remetente soa calorosa e pessoal, desejosa de se manter em contato. Ela pergunta sobre Daphne e sua família; conta sobre seus problemas pessoais e os do país; e pede ajuda, compartilhando suas persistentes dificuldades financeiras, agravadas por um evento inesperado: a situação de saúde de seu segundo filho, um menino nascido em 1987 com a Síndrome de Goldenhar, que exigia intervenção cirúrgica.

Esse foi o motivo da ajuda modesta que Daphne encaminhou algumas vezes pelo correio, não antes de envolver as cédulas em papel carbono para dificultar sua detecção e aumentar as chances de o envelope chegar intacto à destinatária, conforme instruções dadas por esta. Marialice, entrevistada por Ricardo em 2015, lembra-se da contribuição: "a Dáfica me ajudou - pouquinho, mas o pouco dela cresceu, porque foi de coração, não é assim? Quando eu tava em situação difícil eu falava: 'Dáfica, manda um pouco pra mim que eu tô em situação difícil. Você sabe que eu só falo a verdade!'” . Expressivamente, porém, Marialice 
não confiou na força do próprio testemunho ao escrever: anexou uma cópia do laudo médico que detalhava o diagnóstico do menino, com "dermoides epipulbares, apêndices cutâneos pré-auriculares e colobomas palpebrais". Nas palavras da mãe, tão somente um filho que nasceu "sem pálpebra".

Durante a escrita deste texto, Ricardo interroga Daphne a respeito da correspondência que as duas mantiveram e da ajuda financeira oferecida. Há razão para sua curiosidade: entre as mulheres que acessou, Marialice foi aquela que esteve mais ansiosa para se narrar. Ricardo se pergunta se as duas coisas estariam relacionadas, mas conclui que não necessariamente. Marialice narrou-se espaçosamente, sem sinalizar qualquer expectativa nesse sentido. Ademais, bem antes da relação entre Daphne e ela se estreitar, Daphne manuscreveu, após a transcrição da primeira entrevista, ainda em 1981: "Quando saí, Marialice me disse que estava feliz porque as mulheres em meu país conheceriam sua vida; ela acha que as mulheres devem conhecer umas às outras".

Essa observação fornece uma explicação apenas inicial para o empenho narrativo de Marialice, para quem o significado das entrevistas concedidas a Daphne não tem equivalente: o aparecimento dela, com seu gravador, continua sendo um dos eventos mais memoráveis de sua vida. Esse aspecto não apenas impressionou Ricardo, mas informou cada uma das etapas de contato entre ele e a entrevistada. Ao passo em que a maior parte das mulheres custou um pouco a se lembrar de Daphne e a concordar em se encontrar com um desconhecido - que Ihes telefonava conhecendo detalhes de sua vida e pedindo-Ihes um encontro - Marialice não apenas concordou imediatamente, mas disse que o encontraria quando e onde ele desejasse.

Ao chegar a João Pessoa, em fevereiro de 2015, Ricardo soube que Marialice esperava que ele tivesse passado a noite anterior lá; que ela havia preparado o quarto do filho, posto a mesa do café da manhã e o aguardado de prontidão até de madrugada. Nada disso havia sido combinado ou sugerido. Sem nunca a ter encontrado, Ricardo via transferido para si o sentido de importância antes atribuído à sua entrevistadora — ingressando em um circuito que confirma (e expande) a história oral como "uma arte baseada em conjunto de relações" (Portelli, 2016: 12) .

Marialice insistiu obstinadamente que Ricardo deveria mostrar a gravação para Daphne, que iria descobrir os horários em que a ligação internacional era mais barata, para poder telefonar-lhe, e instalar internet em sua casa para escrever-lhe. Depois de 32 anos sem encontrar sua "grande amiga", Marialice descreveu como eram belos os cabelos de Daphne como se ela estivesse diante de si. A maior razão para sua ansiedade, porém, era atualizá-la a respeito de seu progresso; queria mostrar sua casa e insistiu para que Ricardo tirasse fotos. Em sua entrevista de 1981, ela já ansiava por um lugar que fosse seu: "Não quero aguentar 
abuso de ninguém, e também não quero aborrecer", dizia à época, sonhando com um chamado para um conjunto popular. Décadas depois, Marialice transformava Ricardo em mensageiro de seu sonho cumprido, um objetivo conhecido pelos demais. "Você está gravando? Vai levar pra Dáfica? Tu é aluno de Dáfica?", o filho de Marialice pergunta a Ricardo em um dos intervalos da entrevista. Todos sabem perfeitamente quem "Dáfica" é. E a expectativa e inquietude de Marialice levaram Daphne a escrever a Ricardo, após ler seu relato de campo: "Isso me deixa triste — triste por tê-la desapontado de tantas formas".

De qualquer modo, desse encontro ansiado, resultaram não apenas histórias (significativas) de bastidores e sentimentos aflorados, mas algumas horas entrecortadas de gravação e pouco mais de 40 páginas transcritas. Colocadas lado a lado, as entrevistas de antes e de agora suscitam inquietação. Suas narrativas são praticamente idênticas no que diz respeito às expressões utilizadas e aos temas recorrentes (sofrimento, responsabilidade, aceitação). Não é estranho, por si só, que isso aconteça - e que as entrevistas sugiram que quase nada de significativo mudou, no curso de mais de três décadas? E o que isso pode significar? Ausência de desenvolvimento e mudança em sua trajetória? Trata-se de substância, de estilo, ou de ambos?

\section{UMA MULHER INCOMUM}

$\mathrm{E}$ m Brazilian women speak, não temos contato com a história integral de Marialice. Existem nos arquivos pessoais de Daphne, porém, além das transcrições brutas, pelo menos cinco versões da entrevista editada, aos moldes daquelas que foram publicadas - o que sugere a intenção de inclui-la. A incorporação enfática de sua história na introdução da obra deve ter respondido pela opção final.

Assim, é possível que — das muitas personagens - a história de Marialice tenha sido uma das que teve maior ressonância sobre os leitores. Ela alimenta a (influente e sofisticada, acrescenta Ricardo) introdução, mais especificamente a discussão a respeito da literariedade das histórias narradas oralmente. Sem apregoar a permeabilidade ou indistinção entre verdade e ficção, a introdução reconhecia o caráter imaginativo das histórias e a preocupação, explícita ou não, das narradoras com a estrutura e a coerência interna de seus testemunhos. Os leitores eram convidados a compreender as histórias narradas não apenas como janelas para uma realidade em foco, mas como textos plenos.

Remetendo ao experimento de Dennis Tedlock (1983) com a transcrição de falas sob a forma de versos livres, buscou-se em 1988 lançar luz sobre a narração de si como uma arte verbal. A transcrição de longos excertos da entrevista de Marialice em versos, sem a racionalização da prosa, conferiu espacialidade - e, assim, visibilidade — às suas estratégias narrativas: o vai-e-vem cronológico, o estabelecimento de conexões temáticas imprevistas, 
a protelação e prefiguração dos desfechos, a combinação entre discurso direto e indireto, a repetição e a redundância, entre outras. Esse procedimento ajudou a demonstrar a autoridade da narradora sobre seu relato e a relação mútua e íntima entre forma e conteúdo.

Também responde por isso a força narrativa de Marialice, de quem parecem jorrar as descrições de seu cotidiano, os momentos significativos de sua vida, os episódios que tornam comovente, e por vezes divertida, a sua narração de si própria. Em versos ou em prosa, a narração de Marialice aponta para um conjunto de vivências para além da textualidade. Sua história tem a concretude de muitas outras que a paralelizam: deixou o interior da Paraíba rumo à capital para trabalhar e ajudar a família; foi faxineira, cozinheira e costureira; casou-se e foi infeliz; manteve sonhos e planos acesos ao longo da vida.

Em sua primeira entrevista, de 1981, Marialice desfia o trauma familiar que parece orientar muito de sua vida e personalidade: quando tem 15 anos, seu pai "desaparece" e ela passa a ser arrimo de família. Vai para João Pessoa e torna-se a principal fonte de recursos para o sustento da mãe, já velha, aposentada que recebe muito pouco. "Eu tenho obrigação de mandar", diz, mesmo sendo a caçula de dez irmãos. "0 importante de tudo é minha mãe, né? Eu sou louca por minha mãe. Ela sofreu por a gente e a gente tem que sofrer por ela", completa. 0 cuidado com a mãe torna-se uma obsessão na vida de Marialice, que identifica amor e abdicação: "Uma mãe sofrer por a gente e depois a gente ser injustos com ela, a gente não pode".

Marialice não lê a devoção à mãe como resultado da negligência dos irmãos ("é no interior [que eles vivem], não chove, a seca é muito grande... biscate eles fazem, mas emprego fixo quase não tem nenhum, os meus irmãos"), nem do desaparecimento do pai, de quem fala pouco, com tristeza, mas sem mágoa: "Eu não tenho nem mais lembrança, porque eu comecei trabalhar e esqueci, né?". Com o amor pela mãe, porém, nada rivaliza. Como notado em Brazilian women speak, não raro as perguntas feitas servem-lhe como pretextos para voltar à figura materna.

Em 1981, Marialice é casada. 0 marido trabalha como delegado no pequeno município de Catolé do Rocha. Encontram-se a cada oito ou dez dias, quando ele viaja 400 km para chegar ao quarto que ela aluga na periferia da capital, o bairro de Cruz das Almas. Mesmo nesse momento, aos 29 anos, pobre e sozinha, Marialice não teme queixar-se de seus vícios e da falta de companheirismo, embora condescenda tanto quanto em relação ao pai. Uma separação, porém, habita seu horizonte de possibilidades - e ela não manifesta qualquer receio quanto à possível estigmatização por tornar-se solteira. Mesmo falando sobre isso, Marialice retorna à sua mãe: se ela deixasse o marido, não seria para "partir pra outro", mas para "trabalhar e dar melhoramento à minha mãe". 
Marialice é católica, não praticante. Deixou de frequentar missas assim que se mudou para longe de uma igreja. É a mãe que ela idolatra; mas continua sendo Deus, mesmo de longe, que regula sua vida. A certa altura, quando ela afirma que "se o destino da gente vem pra ganhar pouco, a gente tem que cumprir com aquele destino. Tudo depende do destino, né?", Daphne — descrente do fatalismo da interlocutora - pergunta:

Você não acha que a pessoa também tem alguma influência no próprio destino?

Eu acredito que tenha, né? Porque se meu destino veio pra sofrer, eu tenho que ir até o fim sofrendo, né? Se o meu destino [fosse] pra algum melhoramento, acredito que já era pra ter alguma coisa na minha vida. Pelo tempo que eu fui muito esforçada, pode ser que depois de tanto tempo eu tenha algum melhoramento. Depois da velhice, né? Mas, pelo tempo que sofri muito, trabalhei muito, não adquiri nada na vida, e hoje estou indo mais devagarzinho. 0 destino é pra tudo na vida... Se o destino vem até pra morrer agora, eu acredito que eu tenho que morrer, né? Porque isso aí tudo é a sorte que a gente traz.

"I give encouragement between her pauses", escreve Daphne a lápis, às margens da transcrição da entrevista, duplicando o incômodo com sua crença na predeterminação, com sua sujeição à roda da fortuna. Ocorre, porém, como veremos, uma disjunção clara entre o discurso de tom conformista de Marialice e sua futura atitude diante da vida.

A importância, para Marialice, do contato que teve com Daphne em 1981 e 1983 é mensurável não apenas pelas anedotas dos bastidores de sua entrevista a Ricardo. Marialice narra-se livremente - e exorbitantemente — , do momento em que o recebe até sua despedida, e a transcrição da entrevista mais recente revela dois aspectos aparentemente incongruentes.

Em primeiro lugar, há um enorme desequilíbrio: as mais de quarenta páginas da transcrição editada embaçam a alta concentração temática da narrativa. São relativamente poucos os tópicos que ela discute: sua jornada para cuidar do filho; sua relação com o último ex-marido; a morte da mãe; e, no meio de tudo isso, historietas acerca de como ela consegue coisas - sobretudo favores - por ser "querida" e ter "muito conhecimento". A propósito, esse é um aspecto subversivo e verdadeiramente engenhoso de seu modo de exprimir-se: ela conhece muita gente e, por meio delas, alcança seus objetivos; assim, conclui que tem muito conhecimento, mesmo sem jamais ter tido instrução formal.

Em segundo lugar, a narrativa "livre" de Marialice, que parece brotar "espontaneamente", é orientada por uma consciência narrativa abundantemente clara:

- após apresentar seu filho, falar sobre o bairro em que vive e se queixar de dificuldades, Marialice assinala a alternância do modo da conversa informal para 0 modo da entrevista: "Vou te contar, aí a gente começa", diz ela; 
- a narradora ensaia "começar" a entrevista precisamente a partir de quando deixou de dar notícias a Daphne, em suas cartas escritas-orais. No entanto, ela apercebe-se da presença de um outro interlocutor, Ricardo. Opta, assim, começar "do começo". "'Dáfica' sabe. Você não sabe não", diz ela;

- "É melhor começar do começo. Do começo foi assim - é melhor. Do começo eu trabalhava em agricultura. Fui criada e nascida em Araruna. Aí eu saí eu tinha uns quatorze anos. Vim ser babá nas cozinhas dos outros. Meu pai deixou minha mãe passando fome", recomeça, assinalando a origem geográfica, a migração e o trabalho como eixos fundacionais de sua história;

- mesmo sem seguir uma ordenação temática ou cronológica (o que está longe de ser sua prerrogativa, como sabemos), Marialice demarca consistentemente 0 conteúdo "novo" de seu relato. Distingue tais segmentos daquilo que se lembra de ter narrado trinta anos antes, valendo-se de menções frequentes à sua interlocutora anterior: "a Dáfica acompanhou um bocado de coisas", "a Dáfica não te falou, não?", "mandei dizer pra Dáfica".

Diante disso, é compreensível que Marialice insista também que Ricardo atualize Daphne sobre sua vida. Fazendo-o, ela reconhece e sublinha a existência de dois interlocutores distintos; por meio de muletas linguísticas e da combinação entre assuntos remotos e relatos sobre seu passado mais recente, convocados de seu acervo de histórias, responsabiliza-se por criar uma situação de triangulação que pressupõe inexistente em pelo menos dois sentidos triviais. Em primeiro lugar, porque é uma situação da qual, enquanto sujeito e não como personagem registrada em gravações e transcrições, não participou; em segundo lugar, porque um dos interlocutores (Daphne, elo entre os demais) não se encontra corporalmente presente. Ocorre que esse mesmo gesto tem uma implicação, ou mesmo uma motivação, poderosa do ponto de vista epistemológico. No livro How our lives become stories: making selves, Paul John Eakin (1999) afirma que a "narração de si é o ato definidor do sujeito humano", sendo este não apenas um ato descritivo, mas antes "fundamental para a emergência e realidade desse sujeito", com consequências psicológicas importantes para ele. Aqui, Marialice insiste em construir-se subjetivamente nessa relação, não lhe bastando servir como informante pontual de uma pesquisa.

\section{MATERNIDADE: SOFRIMENTO E RESIGNAÇÃO}

ncontrada em três momentos - em 1981 e 1983, por Daphne, e em 2015, por Ricar-
do - Marialice tem a narração sobre os filhos e a maternidade como tema persistente. Páginas e páginas da primeira entrevista, oferecida em 1981, são utilizadas com a descrição 
crua da peregrinação de Marialice em busca de explicações para uma condição de saúde: aquilo que "achava que era uma gravidez, mas não era gravidez. [...] É uma coisa que eu não entendo, né? 0 primeiro filho, eu esperava um filho e aí não era o filho [...]. Era de moles, mãe do vento, eu não entendo isso". A terrível história da falsa gravidez de Marialice — que chega a preparar um enxoval e depois de nove meses descobre não se tratar de um filho - é um dos episódios que Daphne selecionou para transcrever em versos, em seu livro de 1988. Era, de fato, um exemplo notável tanto da ignorância de uma mulher pobre sobre a própria condição de saúde quanto de sua capacidade de comunicá-lo expressivamente, por meio de metáforas, analogias, repetições e, sobretudo, lítotes.

Embora a pseudociese já fosse uma condição conhecida há vários séculos, Marialice demorou a descobri-la: "Quando ia completar o nove mês [...] eu cheguei nervosa que o médico não tinha descobrido o que era. 0 médico não se interessava, né?" . A narradora sequer chegava a assimilá-la inteiramente, senão por meio da negação. Repetia — comunicando de maneira tocantemente simples - a forma pela qual um segundo médico a traduziu: "Filho não é. É uma besteirinha de nada, é um problema que toda mulher tem que espera um filho e não é", o médico teria dito. "Um filho e não é": a expressão volta a aparecer, apenas ligeiramente modificada, quando Marialice relata o encontro com outra mulher que teria tido a mesma experiência. "Uma senhora mãe de seis filhos. E ela falou: um mês dois meses eu comecei de leite na mama... aí não era". Da mesma forma, as explicações para sua condição aparecem na chave da negação: "Minha barriga crescendo [...] e nada de ser neném"; "Eu estava com problemas de câncer na cabeça sem ter"; " Eu fiquei logo nervosa, sem ser câncer, que eu não sinto nada na cabeça".

No momento da entrevista de 1981 - apenas algum tempo depois da pseudociese - Marialice e seu marido estão fazendo tratamentos para possibilitar uma concepção real. Ela sofre a ausência de um filho e a aparente impossibilidade de tê-lo: "Se eu caso fazer o tratamento e não é filho, isso aí é o destino, Deus não quer que eu tenha um filho. Eu não vou mais pensar, inclusive eu não gosto nem de ver essas coisas, não gosto nem de ver neném, nem retrato, essas coisas". Sem relacionar a falsa gravidez com seu próprio estado psicológico diante da dificuldade de engravidar, ela complementa: "Eu peço muito a Deus ter um filho, mas se Deus não quer dar, eu não posso fazer nada, né? Isso é o destino, né? 0 que eu espero é isso".

Dois anos depois, em 1983, porém, a história se complexifica. Marialice retorna ao tema da falsa gravidez, contando que, à época, usava anticoncepcionais, mesmo querendo ter um filho. "Nunca esqueci de tomar [...] Era todo dia", diz. E ela explica as razões, em uma tocante equalização entre desejo e possibilidade: "Eu não tinha condições de criar um 
filho. Porque as condições da gente criar um filho, eu acho que é uma coisa muito séria [...] Criança é um engenho muito fino, né? E eu pensava que eu, como pobre, eu não podia ter filho assim". Mais importante, pela primeira vez Marialice traz à tona a existência de um filho gerado 17 anos antes e deixado com sua mãe — uma omissão significativa na entrevista de 1981, na qual a maternidade foi um tema efetivamente levantado. No âmbito individual, é difícil hipotetizar acerca de omissões — não infrequentes em entrevistas —, mas parece estar indicada a dificuldade de Marialice em lidar com o assunto. Da omissão completa ela chega a um relato econômico, dois anos depois, no qual até mesmo a cronologia é confusa:

Marialice: ... eu tive um filho com 18 anos.

Daphne: Quantos anos você tem agora?

M: Eu tô com 30.

D: E seu filho tem agora quantos?

M: Vai fazer agora 18.

D: Quer dizer, você tinha 12 ?

M: Não, 12 não. Eu tinha 18. 17, eu digo.

D: Você tinha 13 anos quando ele nasceu? Você era criança.

M: Era bem criança. Eu não tinha nem idade de casar. Eu passei sabe quanto tempo sem casar? Passei um ano sem [casar]... dois anos. Que o padre não queria fazer o meu casamento porque eu era muito jovem.

Marialice acrescenta que, de tão jovem, o menino tinha dificuldades para entendê-la como mãe. $\mathrm{E}$, desdizendo o que mal havia afirmado a respeito do uso de pílulas, conta também que, num dos intervalos de uso, havia engravidado e sofrido um aborto espontâneo: "Eu acho que foi problema de alimentação. Deu aquela fraqueza, aquele esgotamento, aquele sofrimento. Aí eu abortei o filho".

Uma criança deixada aos cuidados da mãe, um aborto espontâneo atribuído à pobreza, o forçoso uso de anticoncepcionais interrompendo o desejo de uma nova experiência de maternidade, uma falsa gravidez, a dificuldade de voltar a engravidar: é impressionante como esses eventos só se relacionam sintagmaticamente no discurso de Marialice, que não estabelece nexo entre eles. No entanto, sua posição diante desses eventos segue um padrão recorrente: ela explica as tragédias pessoais com base nas determinações da vida concreta, de forma claramente conformista. 0 destino se abate de maneira impiedosa sobre ela, que apenas o aceita: "Passo necessidade"; "Vou passando sempre aquela vida de sofrimento"; "Tem meses que eu passo [...] necessidade, mas entrego a Deus". No tocante às experiências com a maternidade, os fatos se modificam, mas os padrões de seu comportamento - a exemplo de seus padrões narrativos - continuam sendo os mesmos. Toda a fonte de sofrimento que 
emerge de seu texto oral está ligada não à pobreza, à discriminação, à dificuldade de acesso a direitos sociais em si mesmos, mas ao reflexo disso tudo sobre seus familiares.

Além disso, tanto esses episódios quanto as reações de Marialice a eles são multiplicados nas construções de si que ela produz — suas entrevistas dos anos 1980 são bastante repetitivas e duplicam, em termos praticamente idênticos, o que narra. Há pelo menos dois caminhos que ajudam a compreender essa cristalização de episódios no interior dessa história oral: a repetição e a emoção. Ambos são reconhecidos e analisados pelo neurobiólogo em James McGaugh seu livro Memory \& emotion: the making of lasting memories (2003). Ele aponta que a repetição - efetuada à exaustão de uma prática, até que ela seja sabida "de cor" - é um dos mecanismos mais eficazes para a criação de memórias duradouras. Estas, no entanto, parecem se aproximar das chamadas memórias e procedimentos ou procedurais, ou ainda hábitos — as que o neurocientista Iván Izquierdo descreveu como provendo "da aquisição de habilidades sensoriais e/ou motoras" (2004: 23). McGaugh (2003) reconhece também a emoção como um influxo central para a formação dessas memórias que sobrevivem no tempo. As experiências que nos instigam emocionalmente são aquelas que tendem a permanecer "gravadas" na memória. Tais experiências podem ser eminentemente individuais ou socialmente ancoradas; importa o nível de "alerta emocional" presente no momento de sua aquisição. Esse nível responderá pela consolidação de determinada memória como uma memória de longa duração, que se refere a muitas horas, dias, meses, anos, e que poderá, posteriormente, ser evocada.

No entanto, não é possível traçar tão claramente essa continuidade entre as narrativas dos anos 1980 e a mais recente — até porque, como vimos, Marialice agora investe em um esforço de atualização de sua história. Além disso, uma análise da entrevista concedida a Ricardo aponta para uma característica peculiar. Nas histórias ouvidas por Daphne — quando a entrevistada tinha seus 30 anos de idade — - os relatos combinavam episódios intensos e carregados de dramaticidade com descrições e recopilações triviais. Eles conduziam as histórias de maternidade por dentro de um caminho narrativo repleto de tópicos tão mornos quanto a organização da vida cotidiana.

Na entrevista feita por Ricardo, porém, esses detalhes quase comezinhos estão virtualmente ausentes: o relato é pura intensidade! Se esperamos de uma história usual, regular, que eventos raros e singulares, ou mesmo episódios altamente emocionais, estejam balanceados com o miúdo da vida, a história mais recente de Marialice nos frustra. Um relato eletrizante é imediatamente sucedido por outro. Há um nível de tensão permanente que só intercala suspense e revelação, repelindo o ordinário. Nesse sentido, poderíamos voltar a uma das conjecturas de Daphne, em 1988, e considerar as histórias de uma mulher como Marialice, 
também, como uma criação literária? Se um dos princípios da produção de ficção é o enxugamento criativo, os cortes, o eclipsamento de tudo aquilo que é dispensável ou secundário, não seria incontornável perceber aqui um procedimento análogo? De linguistas como William Labov e Joshua Waletzky a teóricos da literatura como Jonathan Culler, muitos concordam que a mudança em um estado de coisas, ordenada de certo modo e com certo ritmo em um enredo, é o que configura uma narrativa e o que responde por seus efeitos. Aqui, parece que esse traço é tão somente radicalizado.

Psicólogos, neurobiólogos e psicanalistas poderiam levantar outras hipóteses concernentes a esse aspecto narrativo e por conseguinte comportamental: a construção de um sentido biográfico ancorado em uma recordação e em uma narração frenéticas, em certa medida até maravilhosas. Do ponto de vista narrativo, essa mudança no nível do encadeamento dos eventos acompanha uma modificação mais ampla no modelo pelo qual Marialice se narra enquanto mãe. Ela não mais o faz na chave do sofrimento e da resignação, mas sim na chave da luta. Em sua entrevista mais recente, constrói-se não mais como uma mãe conformada com sucessões de perdas, que todavia continuam acontecendo. Diante dessas novas realidades, porém, adquire uma postura heroica e também se narra de maneira heroica, empregando soluções narrativas que transcendem o plano da trama individual. É difícil saber se Marialice tem consciência desse resultado, ou se cultiva essa intenção narrativa. Em seu interessante livro The storytelling animal: how stories make us human, o escritor Jonathan Gottschall (2013: 170) sugere que todos nós tendemos a ser "heróis de nossas próprias épicas". Ele defende que as imagens que construímos de nós mesmos são "constantemente distorcidas por nossas esperanças e sonhos" (Gottschall, 2013: 175) — mas as direções dessas distorções são extremamente variáveis.

Pensemos no relato de Marialice em busca de tratamento para o filho: uma história na qual ela se incumbe do cuidado com a prole, tradicionalmente reservado às mulheres, no espaço privado, mas defrontando repetidamente as instanciações sociais, no espaço público. Para começar, Sérgio é o nome do filho de Marialice, portador da Síndrome de Goldenhar, mas é também o de seu último ex-marido, de um médico recifense, e do funcionário de uma empresa aérea que também é médico — personagens da mesma história, que começa com um sonho:

não sei se você já acredita, mas é uma realidade o sonho, viu? Eu tava deitada na rede, porque eu não podia deitar [na cama], que a barriga era muito grande. Aquele negócio chegou e disse: "Tira teu filho que ele tá cegando", aquela voz, aí eu... tava assim [deitada]. Aí eu [acordei e] saí gritando: "Sérgio, Sérgio [para o ex-marido], Serginho [o filho] tá cegando". Aí ele disse: "Tu tá ficando é doida" ? Eu digo: "Tô não, tô não". Aí quando eu cheguei no meu trabalho e falei: 
"Doutor Aécio, eu tive um sonho". Ele disse: 'Você tem certeza?'". Eu disse, "Eu tive um sonho que meu filho tá cegando. E eu não tenho condições de pagar um ultrassom".

0 relato de um sonho em que antevê a deficiência do filho leva Marialice a ganhar um ultrassom como presente do empregador. No hospital, prestes a realizar o exame, ela depara-se com um novo obstáculo: a reticência do médico:

Aí ele disse: "Quer ver seu filho?" Eu digo: "Eu já sei o que ele tem". 0 doutor ficou incrivel e disse: "Como é que a senhora sabe?". Ele não queria nem mostrar, o doutor. Eu digo "Eu já sei o que ele tem!". "Como é que a senhora sabe? Ou a senhora tá querendo me convencer pra eu mostrar?". Eu digo: "Não, eu tive um sonho e vi meu filho deficiente". Aí ele disse: "A senhora é verdadeira, né?", e eu disse "Sou". Aí ele foi e disse "Olha aqui". Aí ele passou, né? Passou no computador, na televisão, e eu vi ele sentadinho e os óio estufado pra fora, como um cachorro pequinês, no modo de dizer, né?, estufado mesmo pra fora.

De um sonho milagroso e um ultrassom aterrador, Marialice prossegue para um parto com treze horas e meia de duração. Dele, teria saído quase morta, em função de uma hemorragia. Só veria o filho três dias depois: ela, "no balão"; ele, na incubadora, "morre, não morre", porque "nasceu preto da cor de tina. Passou a hora. Foi um sufoco, viu?". Do pós-parto (com inchaços, perdas de líquido, dificuldades de recuperação), Marialice salta para a senda audaciosa da busca pelo direito à saúde do filho. Ela busca atendimento em João Pessoa e no Recife, até finalmente conseguir tratamento público em Belo Horizonte.

E aí o Estado — você sabe que o Estado dava as passagens de avião pra mim, dava a cortesia... Você sabe quanto era a cortesia? Era vinte cruzeiro! Era cruzeiro naquele tempo. Aí eu digo: "meu Deus, eu vou passar necessidade". Fui SOZINHA! E nem eu sei bem por que... mas enfrentei a vida! E o Sérgio [filho] bem novinho dentro do avião, todo mundo empacotava Sérgio, que era muita chuva, eu não conhecia de nada, mas conheci muita coisa... Aí conheci um Sérgio [passageiro] também dentro do avião. Esse não foi Sérgio não; esse foi o Nosso Senhor. Aí ele falou: "Dona!" — eles falam assim — "Quantas vezes, eu tô percebendo, quantas vezes a senhora tá viajando num mês? 0 que é que tá acontecendo com a senhora?".

Marialice enfrenta tempestades, olhares tortos, fome, falta de dinheiro, exigências burocráticas... "Eu tenho lutado com esse rapazinho, viu? Teeeenho... Tenho lutado demais!", reconhece, honrando também a ajuda de companheiros de viagem, motoristas, pilotos, enfermeiros, empresários e, claro, de Sérgio, que identifica com o "Nosso Senhor". "Num canto, prum canto e outro, aí continuaram a me ajudar e graças a Deus, tô contando a história hoje", diz ela, numa frase enunciada com justo orgulho, e que, dentro de uma visada superficial, nos sugeriria que ela viveu e lutou até o ponto da vida em que conta sua história. Ocorre que ela também contou sua história bem antes disso, como forma de seguir vivendo e lutando. 


\section{MEMÓRIAS ÚTEIS}

$\mathrm{E}$ scutando a história de Marialice, Ricardo impressiona-se com sua diligência e dedicação nos cuidados com Serginho, mas também com sua filha mais nova (adotada informalmente, condição que a menina alegadamente desconhece) e com seu ex-marido (para quem Marialice conseguiu oportunidades de formação e colocação profissional). Não é difícil especular que tanta aplicação substitua aquela dedicada à mãe, que, lembremos, nos anos 1980, era nomeada como a pessoa mais importante de sua vida: "Se eu tivesse condições melhor de vida, eu dava mais assistência à minha mãe do que ao próprio marido, porque mãe é tudo na vida. Muito mais do que o marido". Sabendo da morte de sua mãe e intuindo que ela possa ter, de certa forma, liberado - ou mesmo impulsionado - Marialice para outras tarefas, Ricardo pergunta com cuidado: "Agora a senhora já tem menos responsabilidades... Não tem mais que cuidar, por exemplo, da sua mãe, não é?".

A questão não elicita uma reflexão, mas uma nova narração de fatos. Marialice compõe outra sequência frenética, da qual detalhes mínimos das últimas semanas de vida da mãe são suprimidos: só há lugar para o incomum, para o extravagante. Assim, entramos em contato com três histórias de desgoverno: a última alegria da vida de sua mãe, dançando em uma festa de São João como jamais havia feito (o que desperta a desconfiança, em Marialice, de que algo estava errado com ela: "O que é que isso, mãe? A senhora não é disso!"); seu último desejo, frustrado por um desmaio que a levou ao hospital, de se fartar comendo uma galinha inteira; e seu último delírio, o de preparar feijão para um filho, nas últimas palavras ditas antes de morrer: "Tá bom, minha filha. Não aguento mais, não. Dê o feijão do meu filho e não se preocupe comigo".

Salta à vista a competência narrativa da entrevistada, com a qual, em 1988, Daphne (Patai, 2010: 46) se impressionou, escrevendo "estar na presença de alguém que usa com criatividade um instrumento exclusivamente humano: a linguagem". Algumas de suas estratégias foram discriminadas naquele momento: as alternâncias temporais; a criação de conexões imprevistas entre assuntos, a partir de elementos lexicais disparadores; a tática de anunciar um tema e retornar ao anterior, criando suspense; a repetição dos mesmos episódios, com graus de detalhamento diferentes. Agora, nos impressionamos em particular com o caráter altamente controlado de sua narrativa, assinalada por uma economia que se traduz não como síntese, mas como seleção — tão somente daqueles segmentos capazes de cativar o ouvinte.

No livro Fabricando histórias, o psicólogo cognitivista Jerome Bruner (2014: 13) recopilou sua própria teoria para discutir o pressuposto de que "somos tão adeptos da narrativa que ela parece ser quase tão natural quanto a própria linguagem". Bruner perguntou-se sobre 
a existência de uma predisposição narrativa inerente à espécie humana, obviamente reconhecendo a circulação cultural de estruturas sintáticas e de ferramentas narrativas às quais os indivíduos vão se introduzindo desde a infância. E a narrativa — tanto quanto a construção de si por meio da narrativa — é uma arte passível de ser aperfeiçoada. 0 teórico da aprendizagem Ivor Goodson (2019) fala mesmo em "aprendizagem narrativa" e "capital narrativo" como instrumentos poderosos (ainda que enquanto conceitos fugidios) para a busca de conquistas pessoais, para a atribuição de significados à própria vida, na projeção e na construção de futuros melhores.

Marialice está longe de se alhear desse aspecto. Um dos traços de personalidade que ela mais aprecia em si própria é sua intrepidez: ela não tem medo de pedir. Em mais de um momento, ela evidencia como esse apreço construiu-se intersubjetivamente: na relação com os sujeitos a quem pede e por quem intercede: "Quando eu quero o negócio, eu digo: "eu vou ali pedir" [...] É assim que eu faço". Ela orgulha-se do fato de o ex-marido dizer, em voz alta, para ela e para os conhecidos, frases como: "se eu deixar a Marialice [em] definitivo eu tô ferrado, porque ela tem coragem de pedir e eu não tenho".

Essa é uma similaridade crucial nas histórias e nas vidas de Marialice e de Dorotéia, uma mulher recifense entrevistada por Daphne e reentrevistada por Ricardo, com mais de 90 anos. Ambas demonstram ousadia ao recorrer a pessoas em posições sociais superiores em busca de auxílio. Dorotéia relata episódios em que, de maneira firme e altiva, convenceu autoridades políticas e militares a tomar decisões em seu favor ${ }^{7}$. Ambos os casos são expressivos, no nível da narrativa individual, de relações e estruturas sociais bastante conhecidas em macroanálises: as relações de compadrio que resultam em favorecimentos pessoais ao mesmo tempo em que preservam hierarquias sociais e de gênero. São claramente distintas, porém, a compreensões de si governando esses comportamentos semeIhantes: Dorotéia procurava impor-se e fazer-se respeitada, ao passo em que Marialice é consistentemente orientada pela busca de compaixão e afeto. "Eu sou querida, viu?", ela diz a Ricardo muitas vezes ao longo da entrevista - ao final da qual pergunta, sintomaticamente: "Foi isso! Gostou?".

Se Dorotéia vencia pela argumentação e pela impertinência ("Se eu fosse um homem eu era igual a Lampião: cangaceiro e vingador", ela diz), Marialice emprega outra tática: recorre, justamente, à narrativa. Contar sua história é o instrumento de sua luta heroica pelo ex-marido, pelo filho, por sua casa própria e não é coincidência que, entre os anos 1980 e os anos 2010, quando substitui o conformismo com os desígnios divinos (ela dizia, inclusive: "Eu não tinha experiência pra sair pedindo. Eu tinha uma certa vergonha", razão pela qual resignou-se em abandonar o primeiro filho) pelo combate cotidiano, sua narrativa se transforme, 
se aperfeiçoe, tornando-se muito mais concentrada e composta quase que exclusivamente por sequências de "narrativas pregnantes", no dizer de Verena Alberti (2008), histórias "citáveis", imagens cristalizadas, prontas para serem mobilizadas numa narrativa autobiográfica como aquelas que nós produzimos, cooperativamente — mas não apenas nestas.

Da história narrada por Marialice, depreende-se que os episódios perfilados diante de um entrevistador já foram perfilados antes diante dos mais diversos indivíduos que estiveram em condições de Ihe auxiliar. Ela os convoca, em sua construção autobiográfica, para se documentar, como os convocou em seus combates cotidianos, para elicitar compaixão. São práticas narrativas localizadas em um mesmo continuum, sem distinção hierárquica, que se determinam mutuamente e que compartilham um mesmo repertório de memórias úteis, comunicáveis, remodeláveis conforme as necessidades práticas e as pressões sociais. Memórias úteis submetidas a processos variados de avaliação: se, em sua entrevista, Marialice convoca apenas aqueles episódios exemplares, com cores saturadas, isso provavelmente se dá porque, ao longo de sua vida, foram estes os que elicitaram respostas positivas.

É tentador, mas impróprio, imaginar que alguém como ela - uma mulher simples, comum, ordinária no sentido mesmo que a história oral, em seus primórdios, tanto valorizou - tenha tido ao longo de sua vida poucas oportunidades de construir um retrato de si mesma. Ao contrário, sua memória autobiográfica tem sido também uma moeda. Não deixa de ser curioso e instigante, porém, que esses usos da memória - usos que vicejam num território estranho aos dos instrumentos metodológicos e teóricos do pesquisador de história oral - extraiam sua autoridade de um valor que, há muito, relativizamos: "Eu gosto muito da verdade, da realidade", "eu só gosto da verdade", "eu só falo a verdade", diz Marialice, olhando nos olhos de seu mais recente interlocutor. "A senhora é verdadeira", "a gente vai te ajudar, só porque tu falou MUITA verdade", ela se lembra ter ouvido de pessoas que lhe auxiliaram, redirecionando-nos do sentido de uma distinção como aquela entre verdade histórica e verdade narrativa feita por Donald Spence (1982), rumo a uma compreensão clara sobre o papel da verdade, na vida, em sua dimensão prática.

Se, em 1988, notou-se Marialice como uma narradora que moldava sua história centrando-se nos episódios e eventos que contribuíam para a construção de uma imagem de si coerente, está claro que esse processo seguiu em curso, confirmando o entendimento de Agnes Hankiss (1981) de que se trata de uma ação interminável, na qual novos modelos ou estratégias são continuamente avaliados e selecionados. No caso de Marialice, isso se dá não pela revisão da interpretação de seu próprio passado - como se poderia, em princípio, pressupor - mas pela sua reafirmação, tanto quanto pela convocação de novos elementos capazes de contribuir para o molde de uma história coerente ou, em suas 
palavras, verdadeira. Continuidade e mudança são temas caros a todos nós — enquanto seres que se pensam e se narram — e, embora mudanças tenham de fato ocorrido na vida de Marialice (inclusive em termos de suas conquistas materiais), o que sua história oral expressa e sublinha são as continuidades.

Conflitos de interesse: nada a declarar.

Fonte de financiamento: Conselho Nacional de Desenvolvimento Científico e Tecnológico (CNPq).

Contribuições dos autores: Santhiago, R.: Administração do Projeto, Curadoria de Dados, Escrita - Primeira Redação, Escrita - Revisão e Edição, Investigação, Metodologia, Obtenção de Financiamento; Patai, D.: Administração do Projeto, Curadoria de Dados, Escrita - Primeira Redação, Escrita - Revisão e Edição, Investigação, Metodologia, Obtenção de Financiamento.

\section{NOTAS}

1 A pesquisa foi financiada pelo Conselho Nacional de Desenvolvimento Científico e Tecnológico (CNPq) por meio do projeto "A mulher brasileira fala, 30 anos depois: Memória, intersubjetividade, método", aprovado no Edital Universal 2014 (processo 462197/2014-0). Contou com apoio financeiro complementar da University of Massachusetts, Amherst, e do Programa Auxílio à Pesquisa para Docente em Início de Carreira (PAPDIC), da Universidade Estadual de Campinas (onde Ricardo era docente à época).

2 Aqui, empregamos nossos nomes próprios, em terceira pessoa, quando nos referimos a experiências ou observações individuais, dando consequência ao sentido de subjetividade e intersubjetividade característico da pesquisa de história oral; reservamos a primeira pessoa do plural para seções fundamentalmente descritivas e para pontos de vista convergentes.

3 Lembre-se, ainda, dos livros com modelos de cartas - comerciais, de amizade, de amor, de pedidos — produzidos por editoras populares como a editora Luzeiro e capilarizados numa rede de distribuição popular por todo o país. Jerusa Pires Ferreira (2010) trata desses livros em suas pesquisas sobre editoras populares.

40 artigo foi traduzido para a língua portuguesa como "Problemas éticos de narrativas pessoais, ou, quem vai ficar com o último pedaço do bolo?", incluído em História oral, feminismo e política (Patai, 2010). 
5 Norma também foi entrevistada por Ricardo, no segundo momento de pesquisa. Em novembro de 2020, Norma faleceu, aos 73 anos, devido às consequências de um câncer nos pulmões.

6 Em sua leitura sobre a centralidade da "relação" na prática de história oral, Portelli identifica quatro ordens constitutivas: "1. A relação entre entrevistadores e entrevistados (diálogo); 2. A relação entre o tempo em que o diálogo acontece e o tempo histórico discutido na entrevista (memória); 3. A relação entre a esfera pública e a privada, entre autobiografia e história - entre, digamos, a História e as histórias; 4. A relação entre a oralidade da fonte e a escrita do historiador" (Portelli, 2016: 12). Como se verá no caso de Marialice, outras relações conglomeram-se a estas, que para Portelli, consistem certamente em uma abertura conceitual, não em um rol prescritivo ou exaustivo.

7 A respeito dessa narradora, publicamos o capítulo "Dorotéia: reavendo o passado" (Santhiago e Patai, 2021).

\section{REFERÊNCIAS BIBLIOGRÁFICAS}

ALBERTI, V. "Narrativas pregnantes" como "jogos de linguagem": possibilidades da história oral à luz da teoria da linguagem de Wittgenstein". História Oral, Rio de Janeiro, v. 11, n. 1-2, p. 127-148, 2008. https:// doi.org/10.51880/ho.v11i1-2.154.

BRUNER, J. Fabricando histórias: direito, literatura, vida. São Paulo: Letra e Voz, 2014.

EAKIN, P. J. How our lives become stories: making selves. Ithaca: Cornell University Press, 1999.

FERREIRA, J. P. Cultura das bordas: edição, comunicação, leitura. Cotia: Ateliê, 2010.

GOODSON, I. F. Currículo, narrativa pessoal e futuro social. Campinas: Editora da UNICAMP, 2019.

GOTTSCHALL, J. The storytelling animal: how stories make us human. Nova York: Mariner Books, 2013.

HANKISS, A. Ontologies of the self: on the mythological rearranging of one's life story. In: BERTAUX, D. (org.). Biography and Society. Beverly Hills: Sage, 1981. p. 203-209.

IZQUIERDO, I. Questões sobre memória. São Leopoldo: Editora Unisinos, 2004.

MCGAUGH, J. Memory \& Emotion: the making of lasting memories. New York: Columbia University Press, 2003.

PATAI, D. Ethical problems in personal narratives, or, Who should eat the last piece of cake? International Journal of Oral History, Westport, v. 8, n. 1, p. 5-27, 1987.

PATAI, D. Brazilian women speak: contemporary life stories. New Brunswick: Rutgers University Press, 1988.

PATAI, D. Oral history. In: SMITH, B. G. (org.). Encyclopedia of women in world history. Oxford: Oxford University Press, 2008. p. 388-391. 
PATAI, D. História oral, feminismo e política. São Paulo: Letra e Voz, 2010.

PORTELLI, A. História oral: uma relação dialógica. In: PORTELLI, A. História oral como arte da escuta. São Paulo: Letra e Voz, 2016. p. 9-25.

SANTHIAGO, R.; PATAI, D. Dorotéia: reavendo o passado. In: ROVAI, M. G. de O. (org.). Escutas sensíveis, vozes potentes: diálogos com mulheres que nos transformam. Teresina: Cancioneiro, 2021. p. 237-258.

SPENCE, D. Narrative truth and historical truth. New York: Norton, 1982.

TEDLOCK, D. Learning to listen: oral history as poetry. Boundary 2, Durham, v. 3, n. 3, p. 707-728, 1983. https://doi.org/10.2307/302186. 